\title{
آى > > >
}

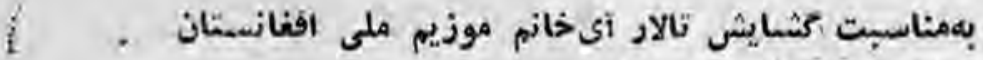
كابل : جوزاي · 157

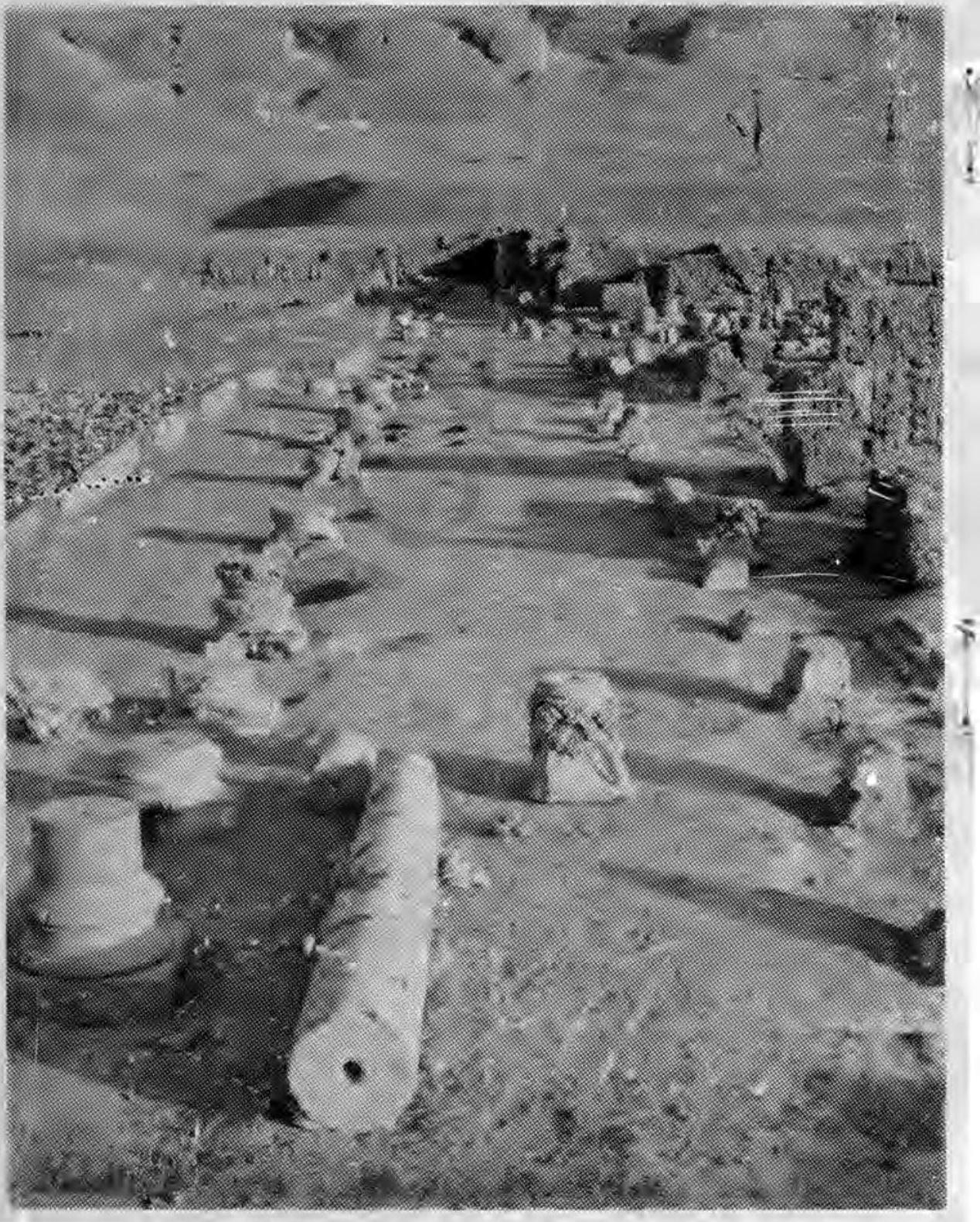




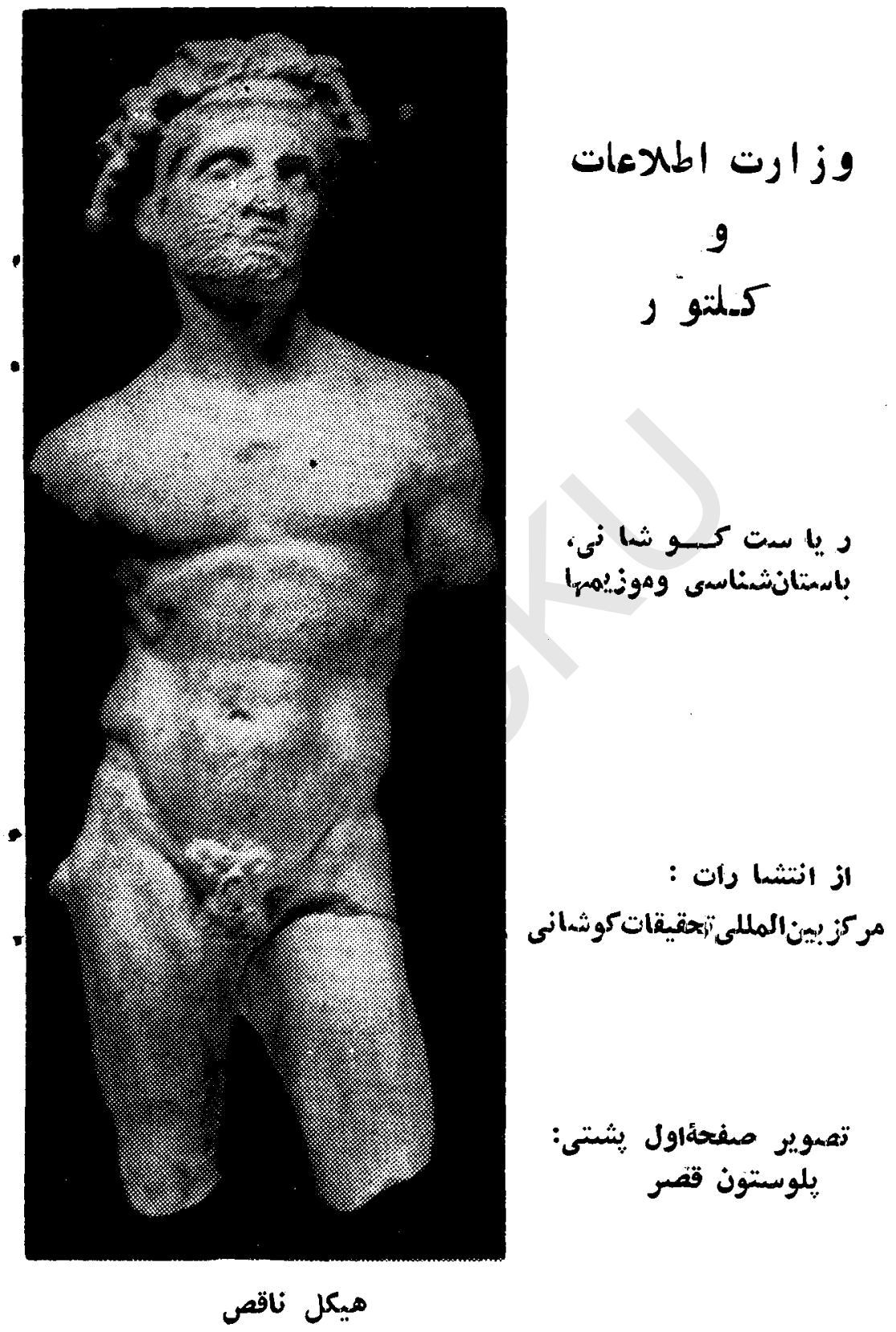




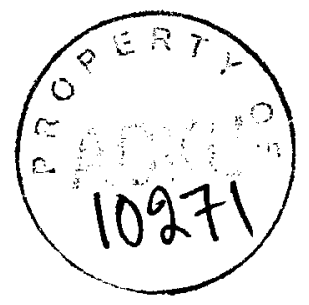

دآى خانسم د آ ألار رود ننسه ار تو ن د دان

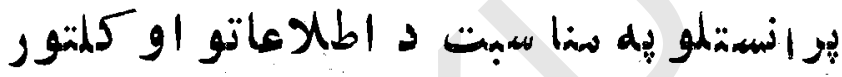

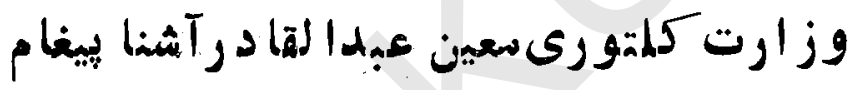

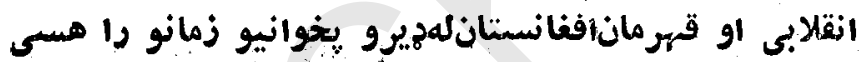

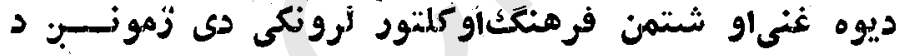

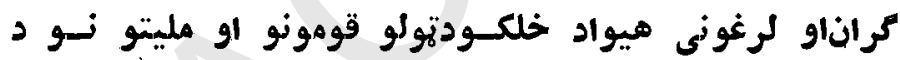

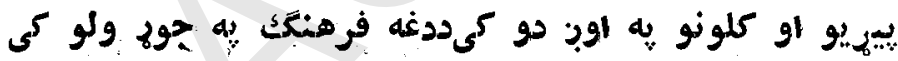

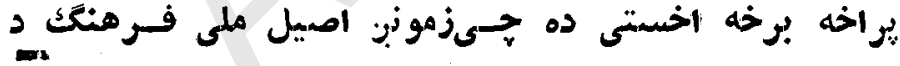

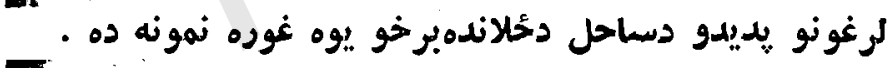

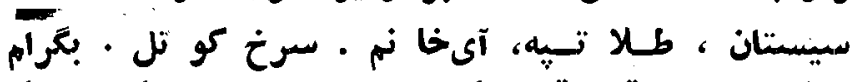

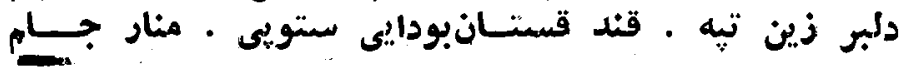

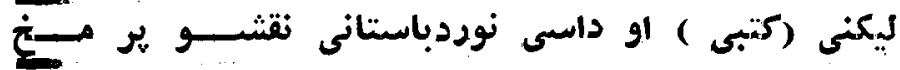

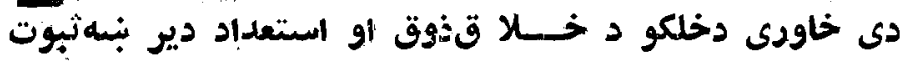

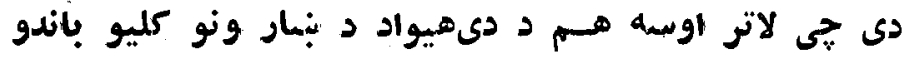

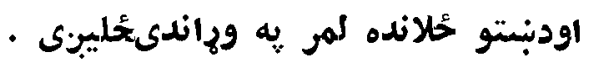

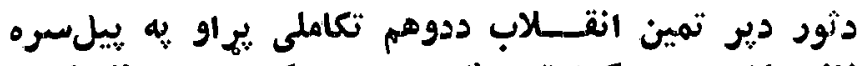

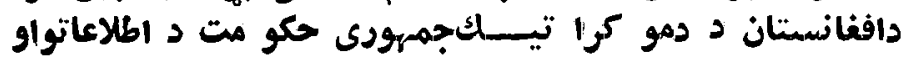

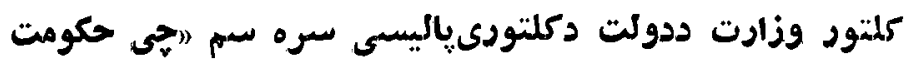




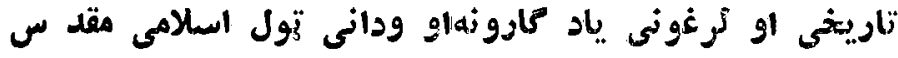

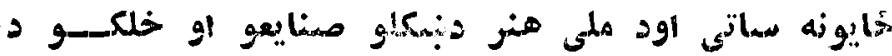

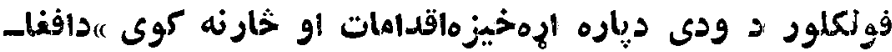

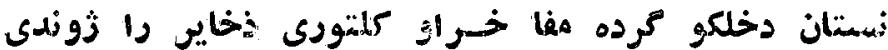

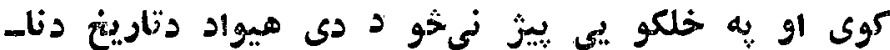

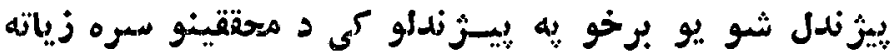

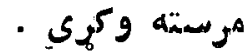

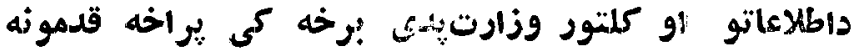

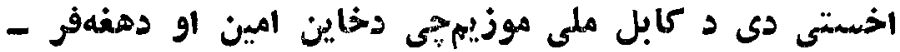

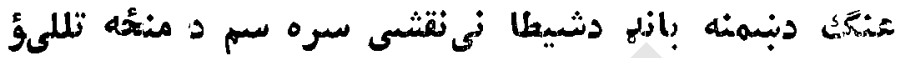

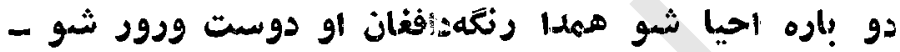

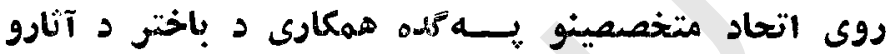

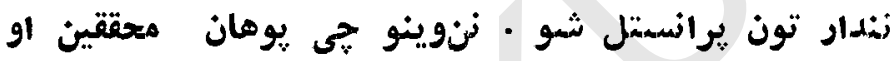

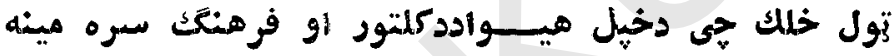

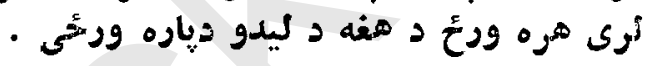

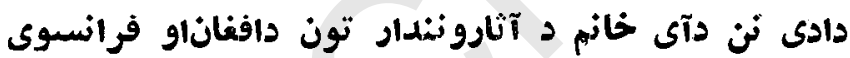

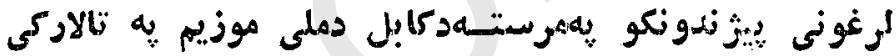

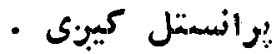

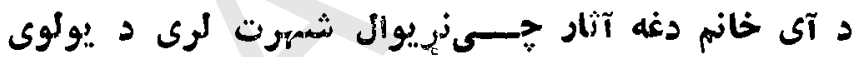

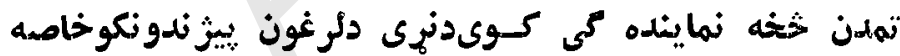

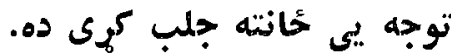

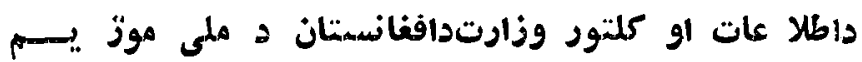

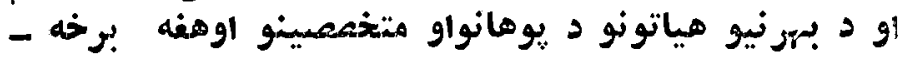

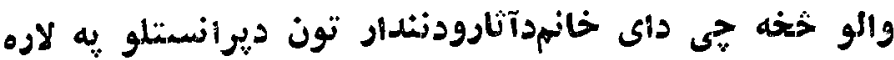

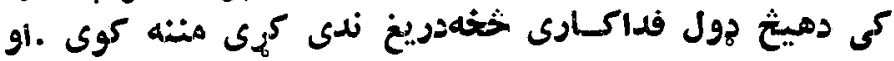

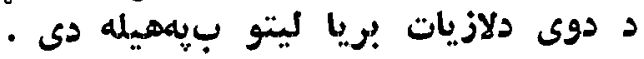




\section{آلى خان نسم \\ ميعاد كاه باستا نسى نماريخ}

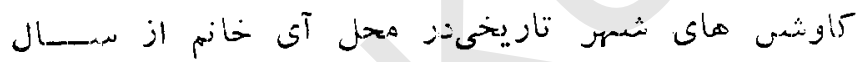

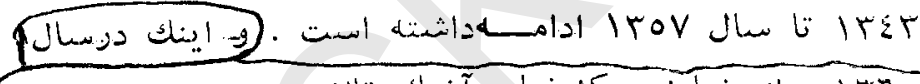

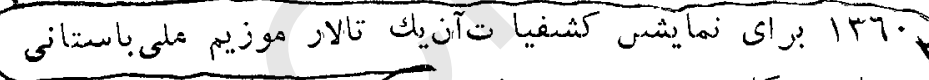

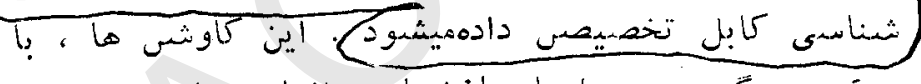

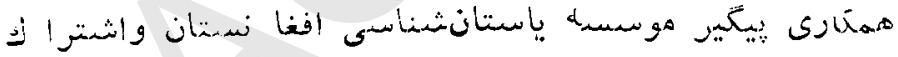

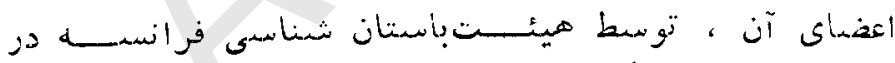
افغانستان صوزت كرفته است هيت.

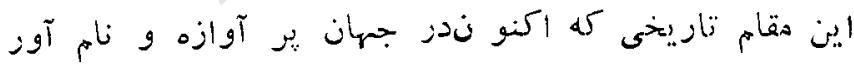

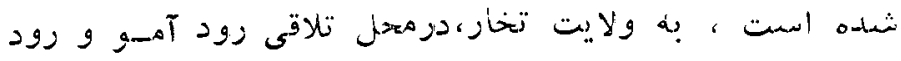

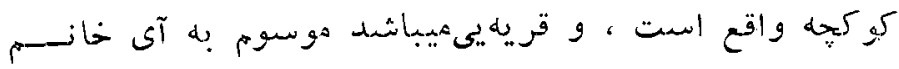

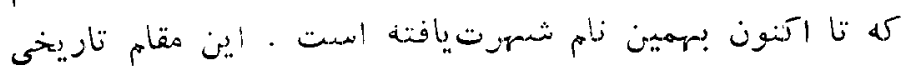

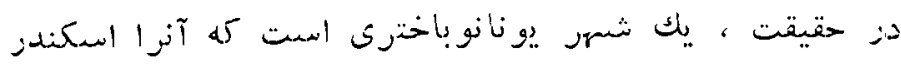

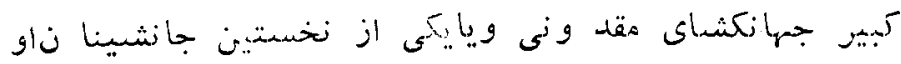

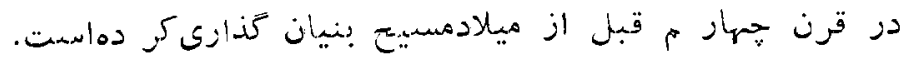

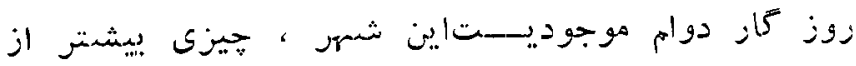

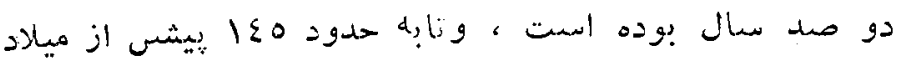




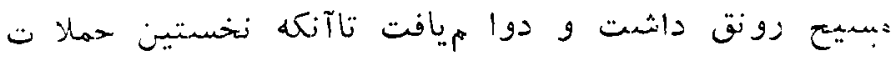

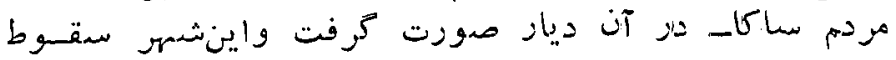

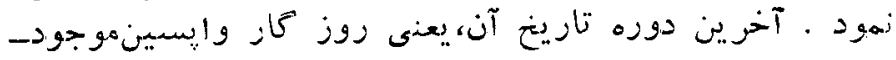

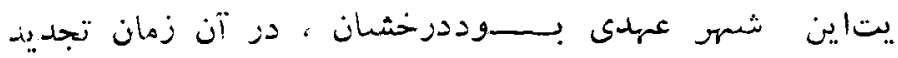

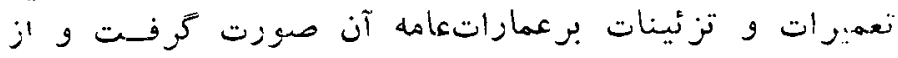

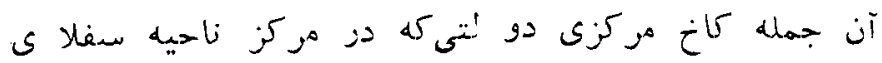

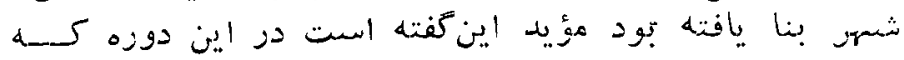

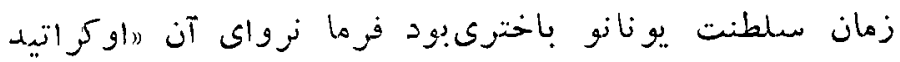

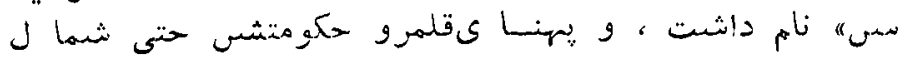

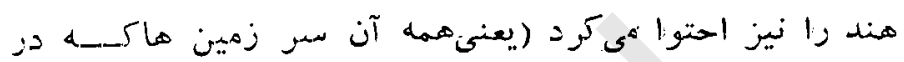

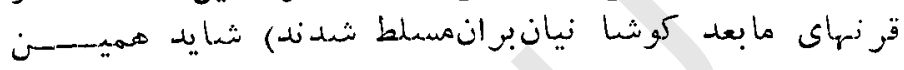

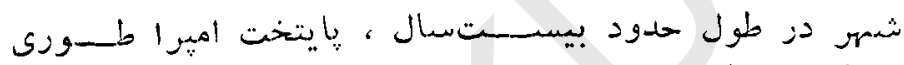

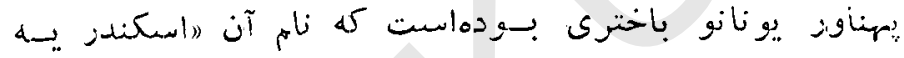

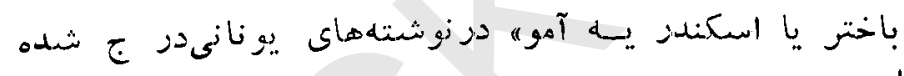

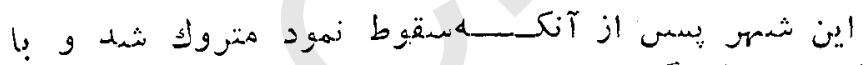

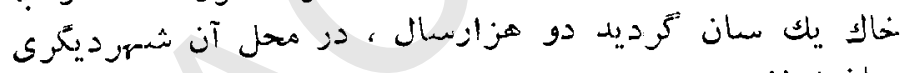

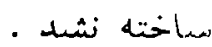

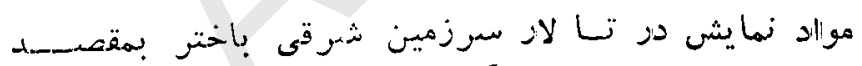

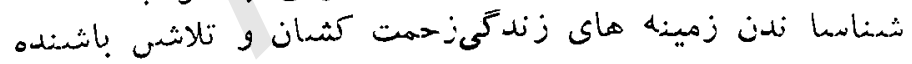

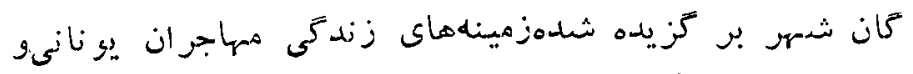

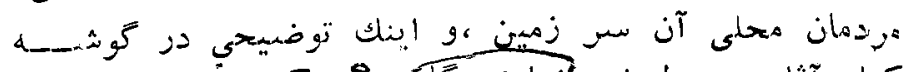

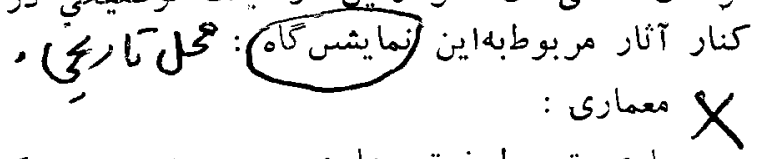

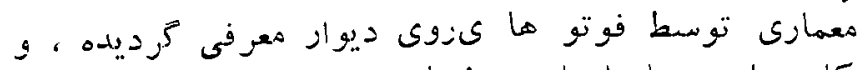

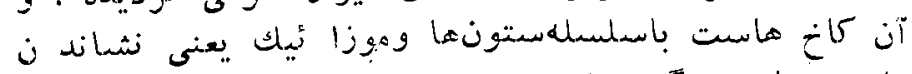

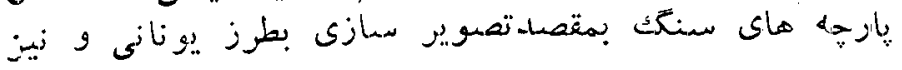

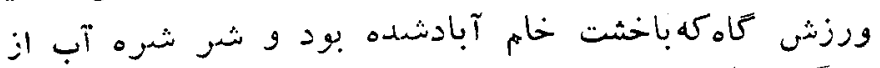

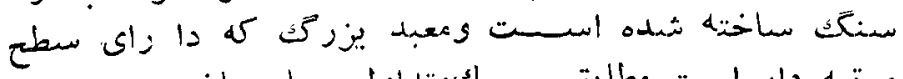

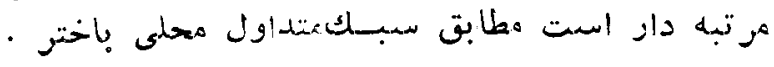




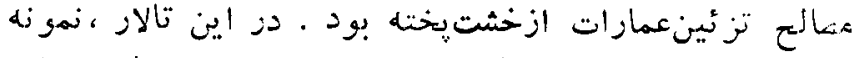

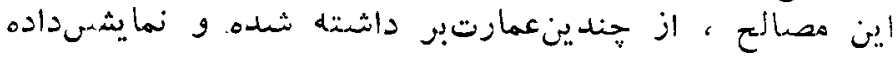

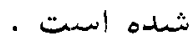

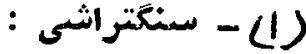

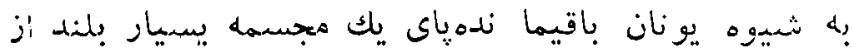

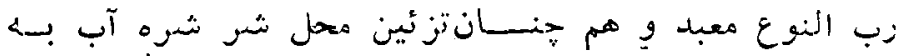

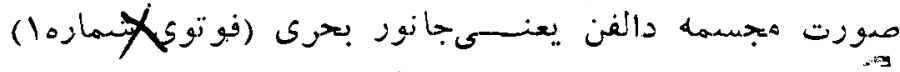

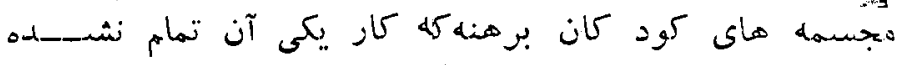

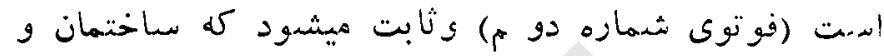

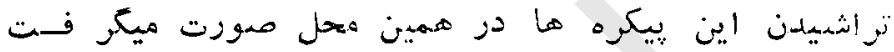

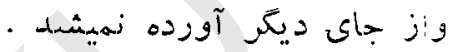

$$
\begin{aligned}
& \text { : أن - (q) }
\end{aligned}
$$

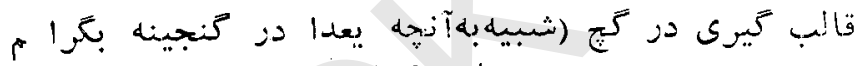

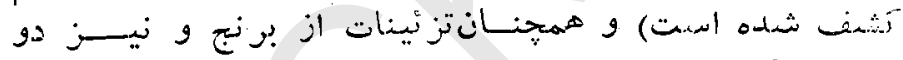

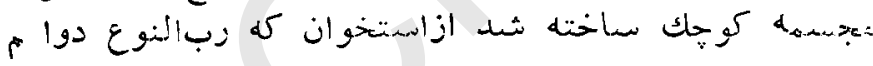

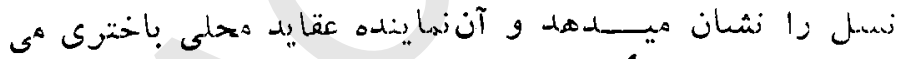

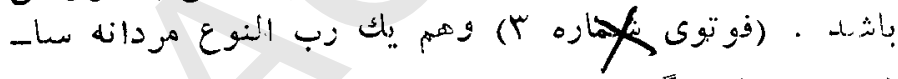
ختهه شده ازسنكَك.

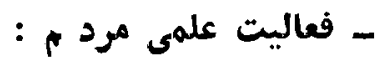

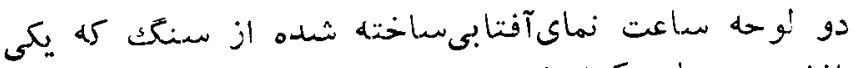

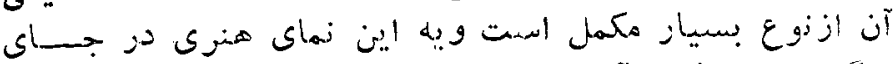

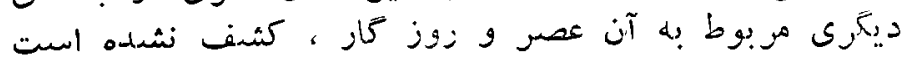

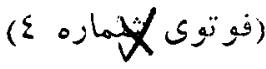

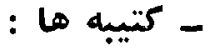

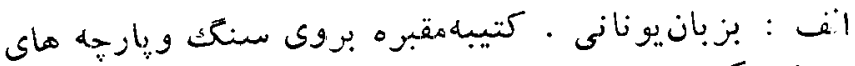

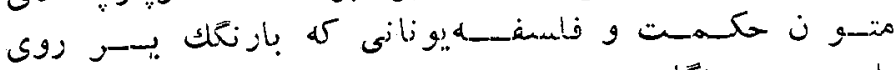

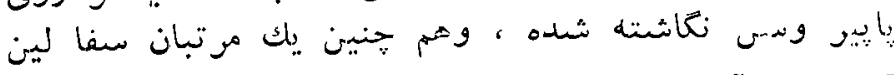

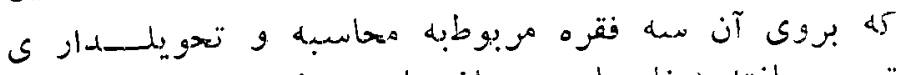

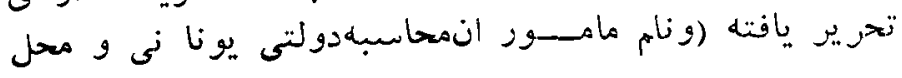




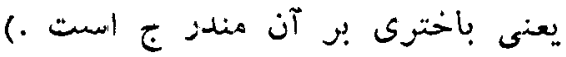

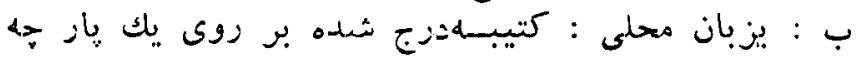

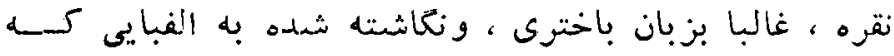

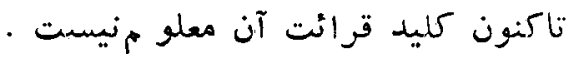
ظروف قيمتى : ناند

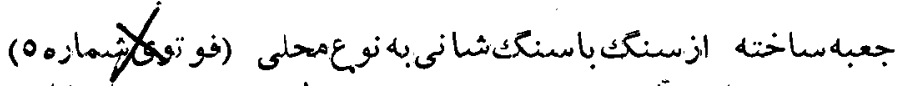

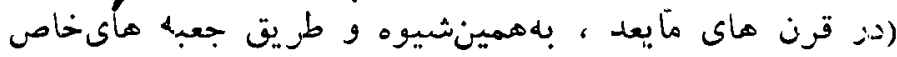

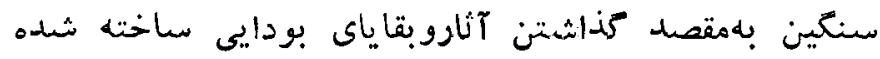

است .)

همجنان عطر دانى سا ختلهثده ازسنك و رخامي بهمقد

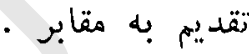

: ظروف عادى : نمدئ :

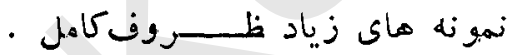

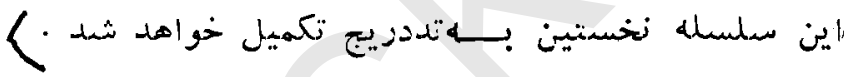

$-7$ 
- Arte minenre : moulages en platre, senblables a ceux que l'on trourera plus tard dano le trésox de de Bégram; ornements en bronze. Les oultes pratiqués par la population locale sont représentés par deux otatuettes en os d'une désse de la f́condité et par une idole masculine on pierre.

- Activités scientifiques : deux cadrans solaires en plerre, dont l'un d'un modèle très perfectlonne, Inoonna jusque-1à.

- Doouments fócits : a) en Brec : Inscription funcralre gravóe sux flarres pregments de textes phllosophlques, fortis a l'oxvers sur papyrus, jarre portant trois insoriptions nomptables qui mentionnent des fonctionnaires grecs et bactriens.

$$
\text { b) en langue locale: }
$$

Ingcription Incisée sur un lingot d'argent, probablement on langue bactrlenne notée dans un alphabet non encore déchiffré.

- Valsselle de luxe : cassette on plerre arec incrustations, de traditi on looale, ancetre des rellquaires bouddhiques; boutellies a parfum en albatre destinées à des offrandes funéralres.

- Vaisselle ordinaire : abondant echantillonage de vases entiers

Cette premlère sórie d'objets sera progressivement complétée. 
notamment le palais qul occupe le centre de la ville basse. C'est le moment où le royame grécobactrien, sous le règne d'Eucratide, s'etendalt sur l'Inde du Nord, occupent le même territoire que celut sur lequel plus tard règneront les Kouchans, et il est possible qu'AI Khanoum ait bté alors pendant une vingtaine d'années la capitale de cet immense empire.

Lo choix de documents prósenté dans cette "Salle d'AI Khanoum" vise a lllustrer 108 différents domaines dens lesquels s'est exercée l'activité des habitants d'AI Khanoum; Immigrants erocs et population loosle :

\section{- Architecture monumentele : ello est éroqué} par les photographles au mur palais arec sa colonnade et ses mosalques a la grecque, gymnase en brique crue, fontalne en pierre, grand temple arec plateforme a degrés de tradition locale bactrienne. Des bléments de déoor architectural en terre culte, provenant de plusleurs betiments, sont également présentés dans la sallo.

- Sculpture en pierre de tradition grecque : pied de la statue colossale de la divinité du temple; gargoullles de la fontaine (dauphin, masque de théatre) statues f́́minines drapées; statres de jeunes homes nus dont l'une, inachevfe, prouve que ces oeurres étalent fabriquées gur place et non pas importées. sur 


\section{SATHE D'A KHaNOUI}

Le foutlle d'AI Khanoum, is la quelle est consacrée la nouvelle salle du Musée de Kaboul, s'est déroulée de 1964 à 1978. Flle a eté nené par la Delégation Archéologique Frangelse on Afghantstan (D.A.F.A.) arec la collaboration oonstante de l'Institut Afghan d'Archéolog̉e qui a chaque année délégué un de ses membres sur 1e forille.

Le site, qui béneficie maintenant d'une renomé mondiale, se trouve dans la province de Takhar, au confluent de l'Amu-Darya et de la Koktcha. Il g'agit d'une ville grécobectrienne fondée solt per Alexandre lul-meme, solt par l'un de 808 premiers suocesseurs, et dont l'existence se poursuift durent un pen moins de dewx siecles, jusqu'en 145 ar. J-C environ, date laquelle elle fut abandonnée probablement sous la pression des premières invasions Saka. La derniére periode de l'histolre de la ville fut apperemment la plus brillante et fut marquée par un raste programe de reconstructions et d'embellissements qui effecte tous les betiments publics, 


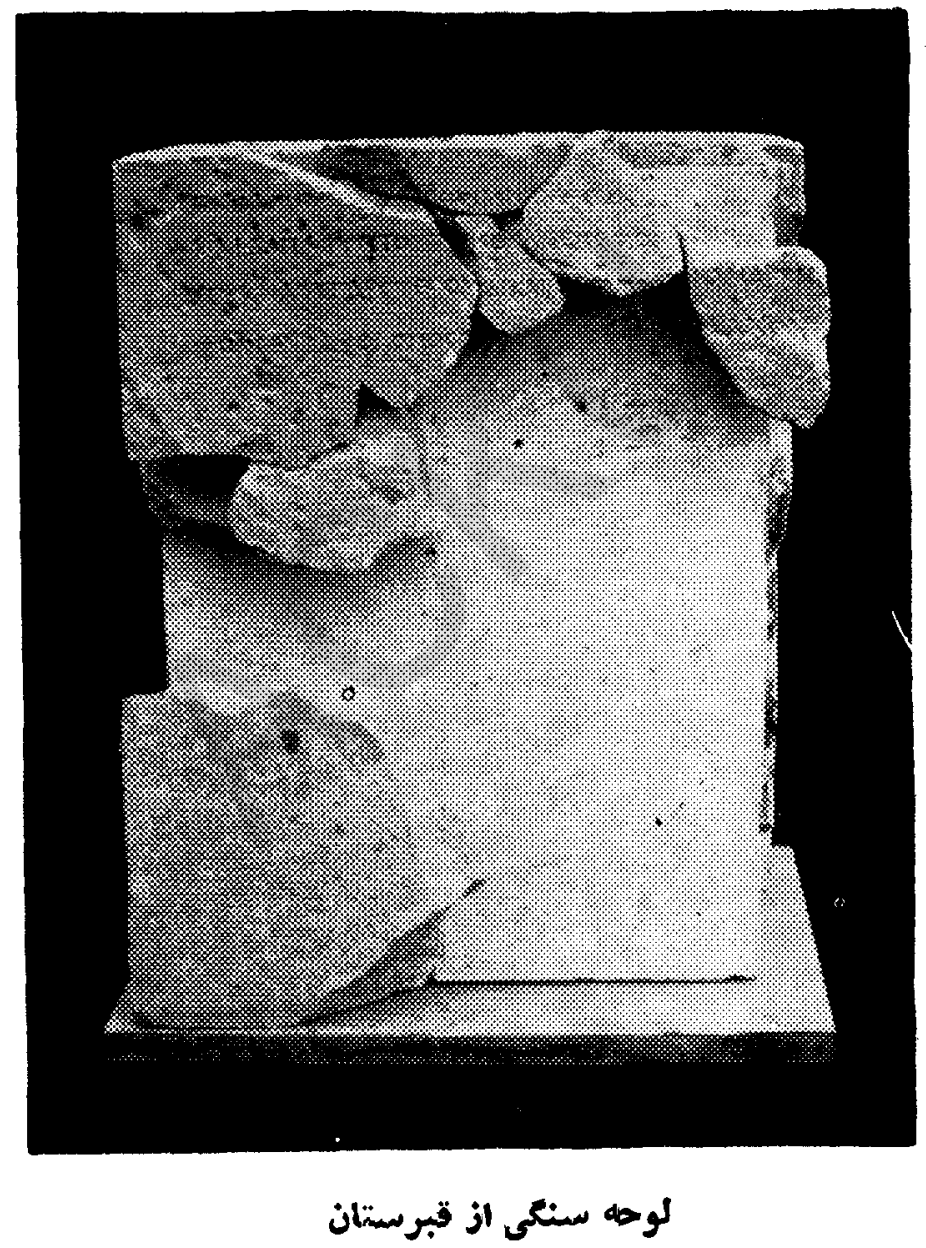




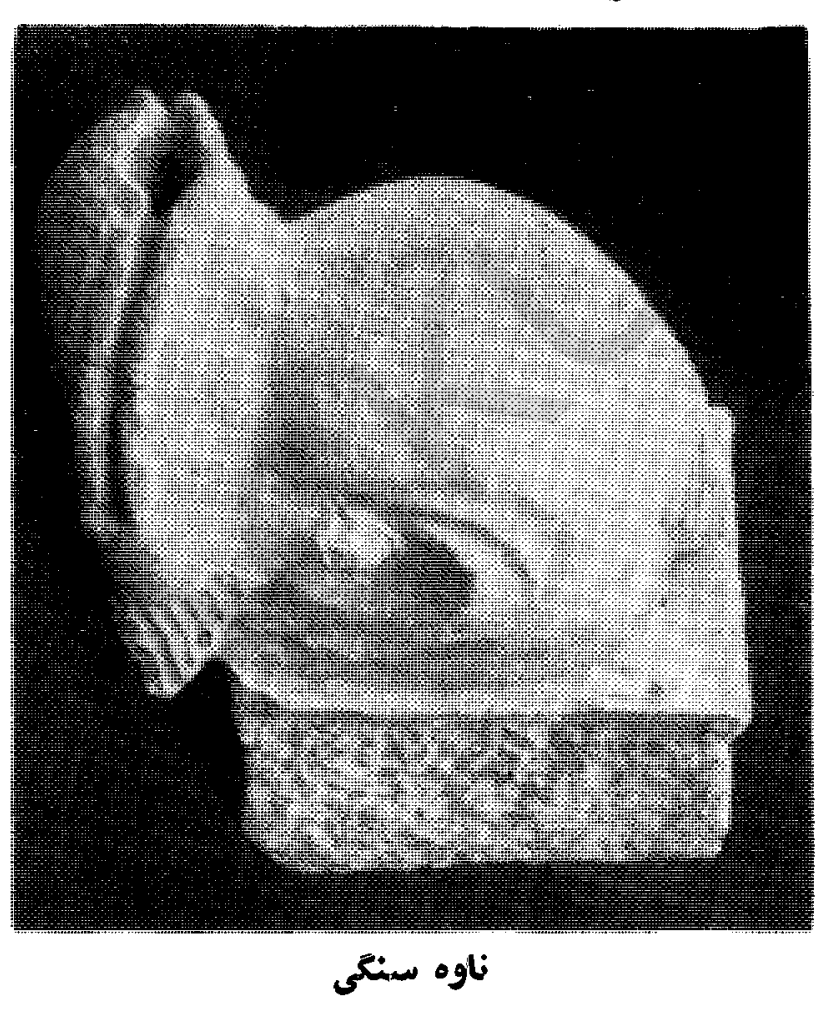



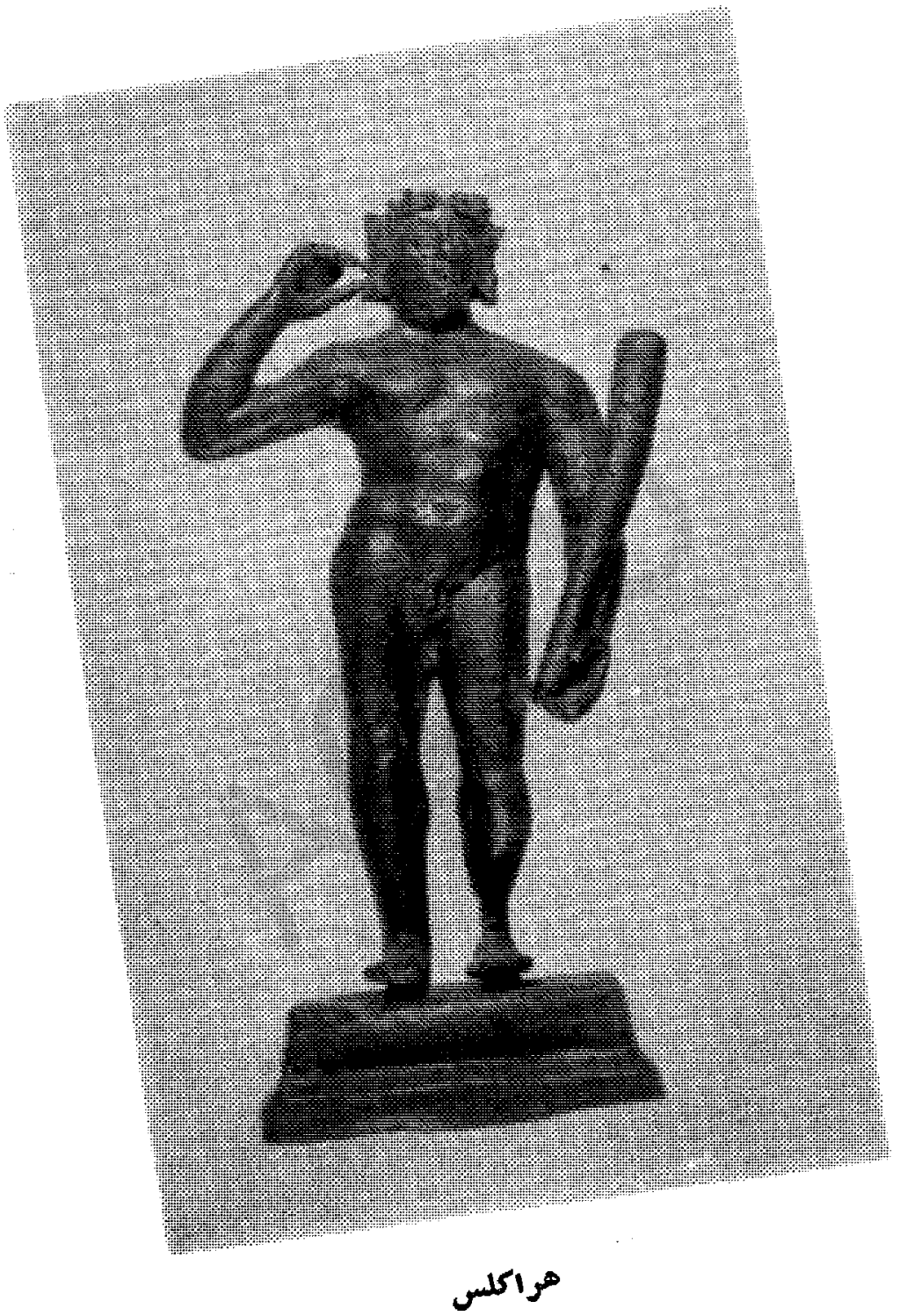


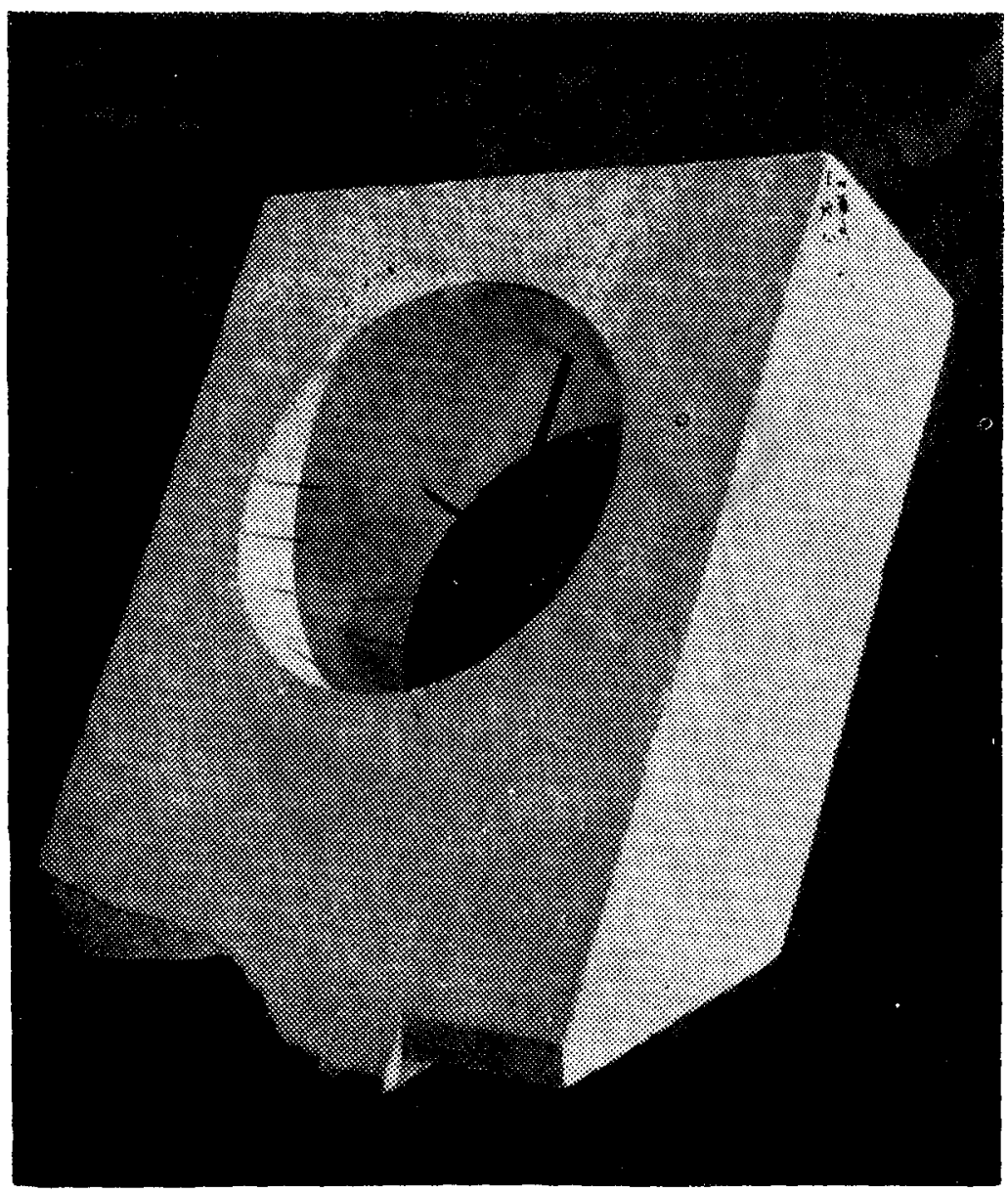

ساعت آفتابى منحصر بهفرد 


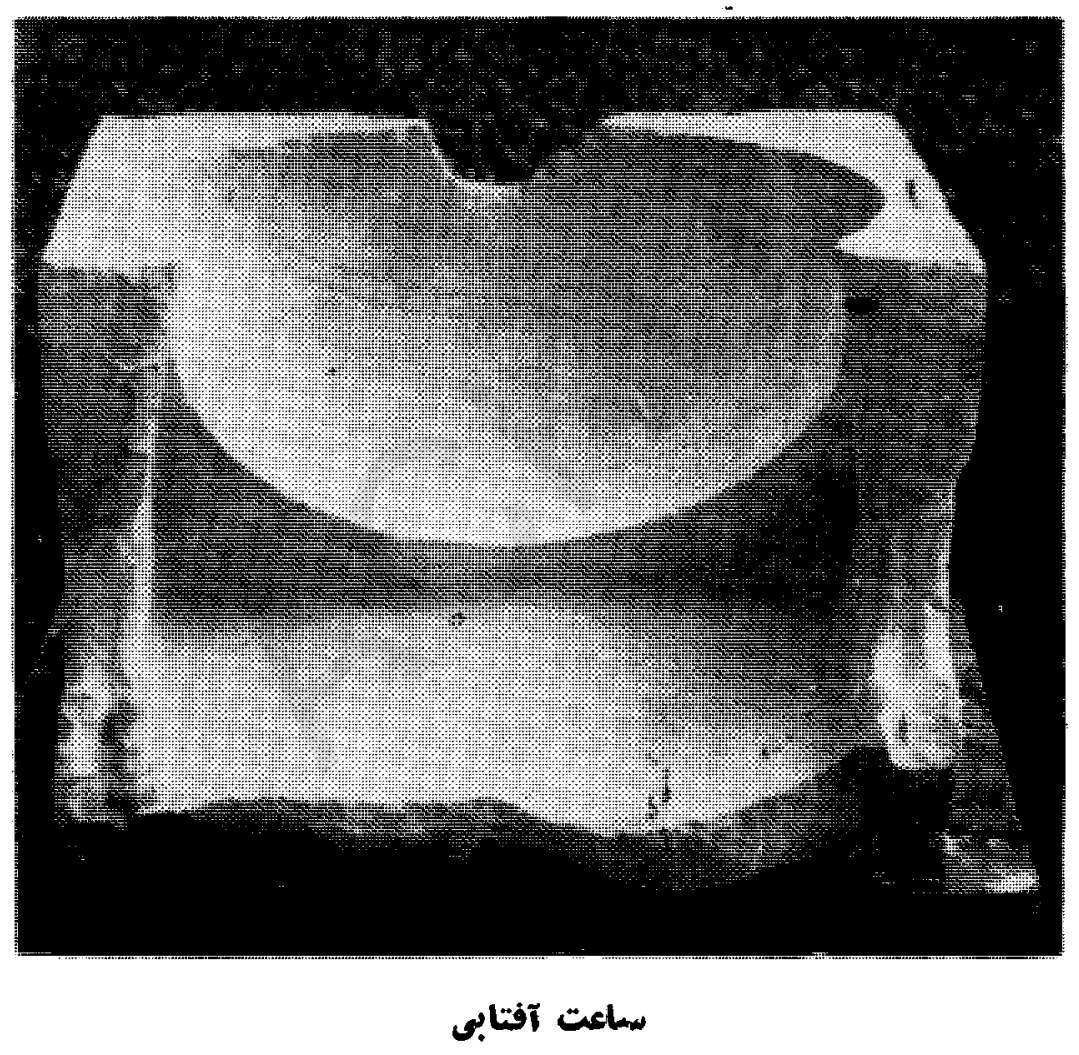




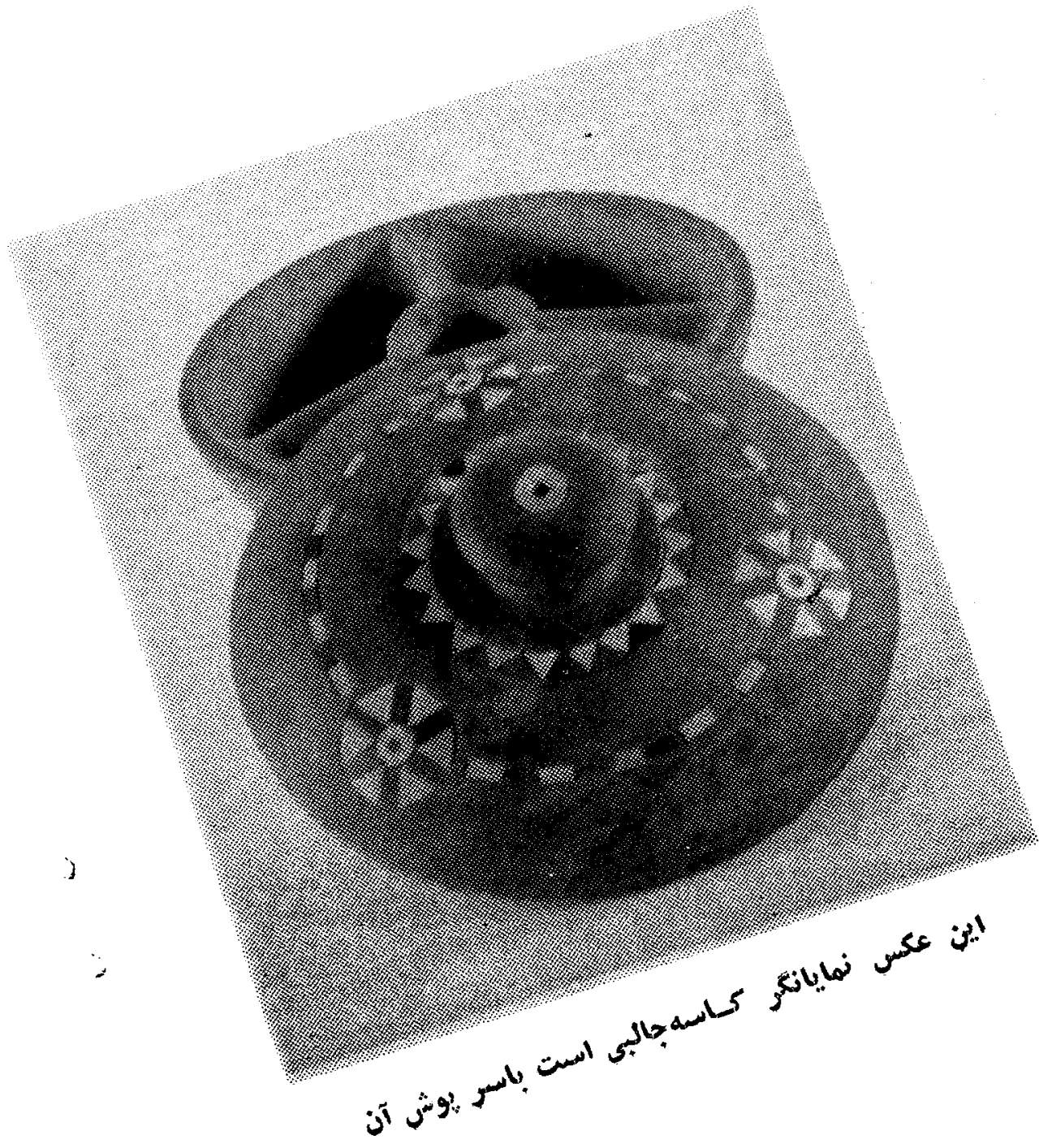




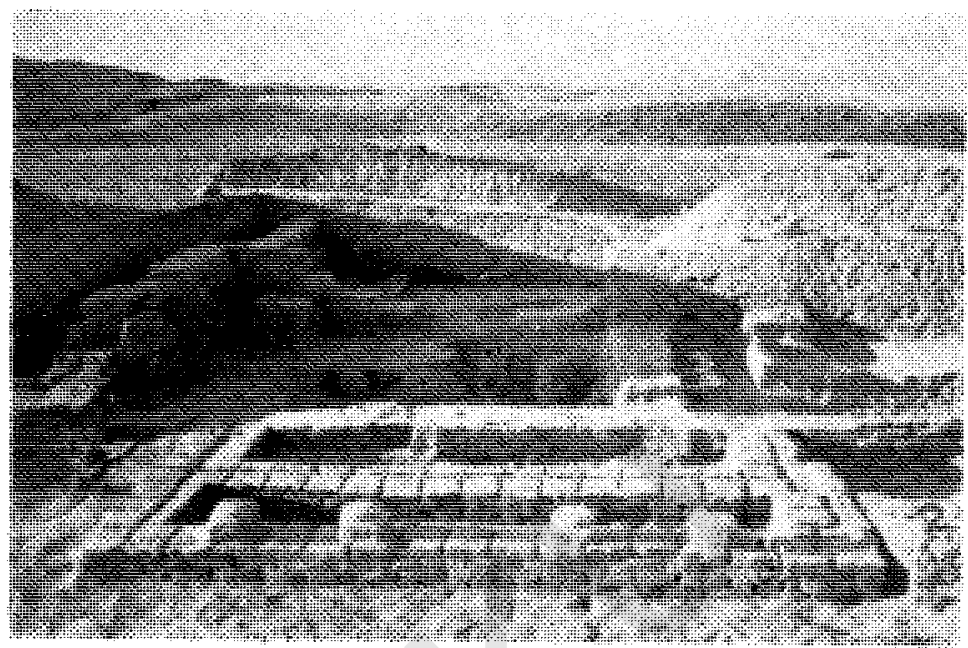

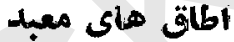

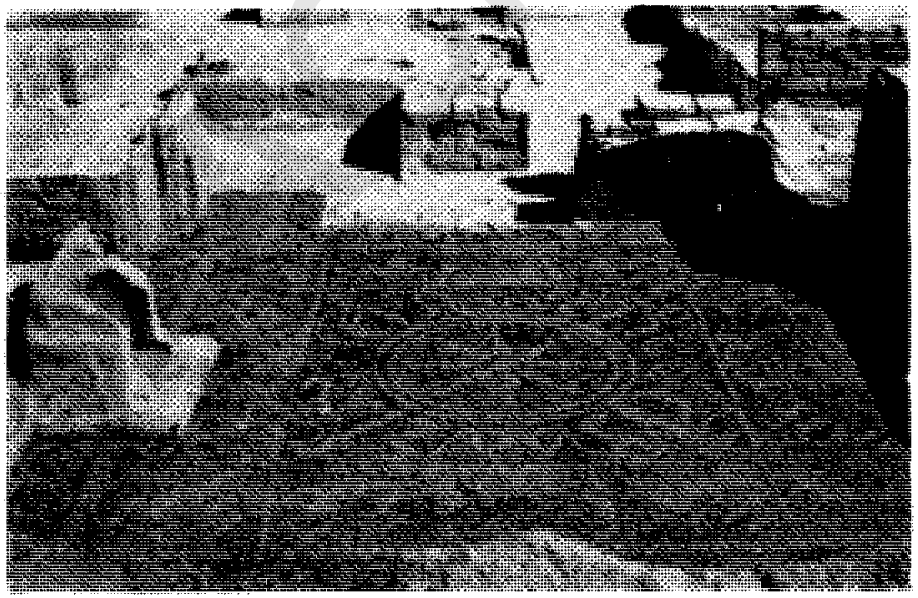



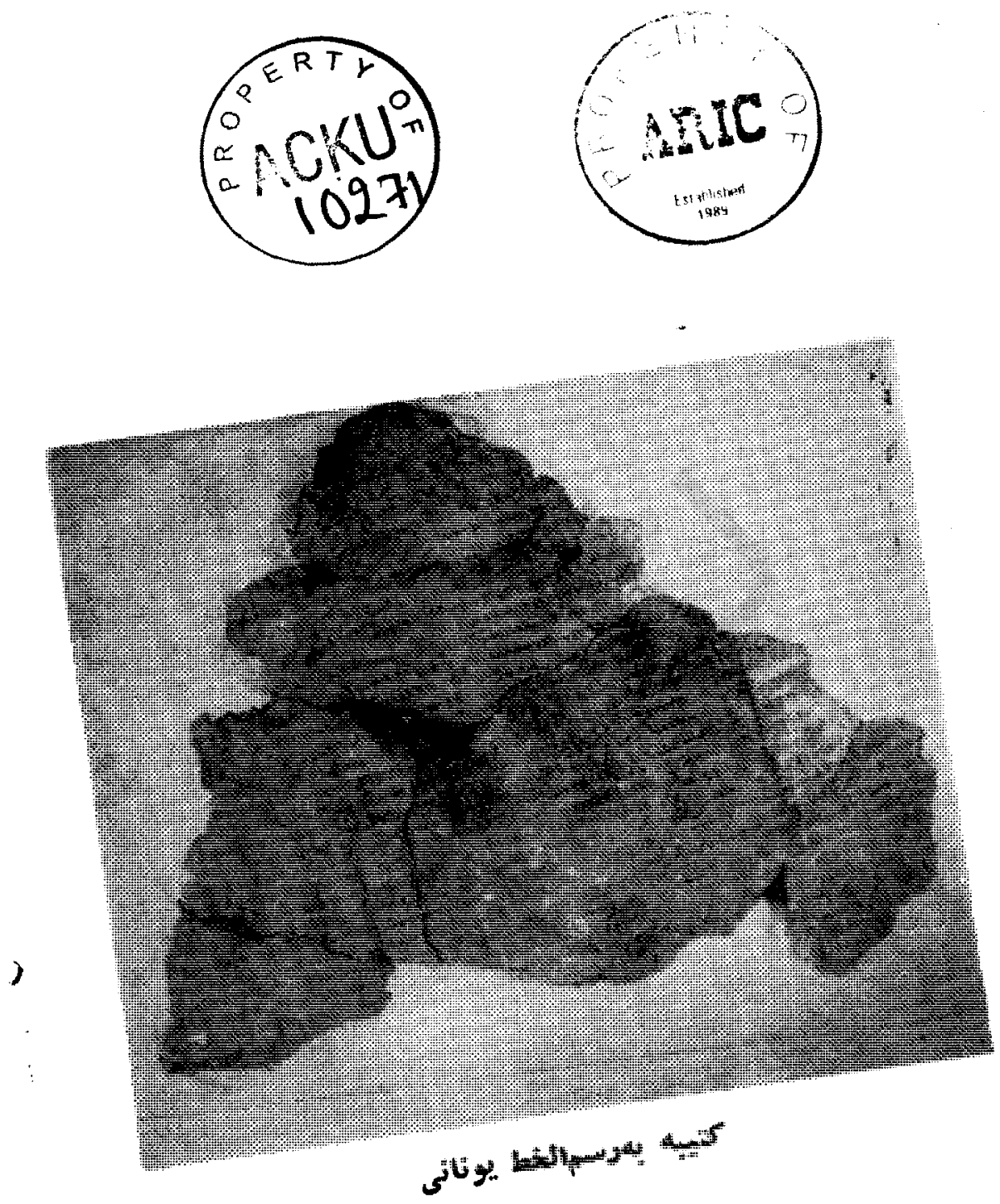


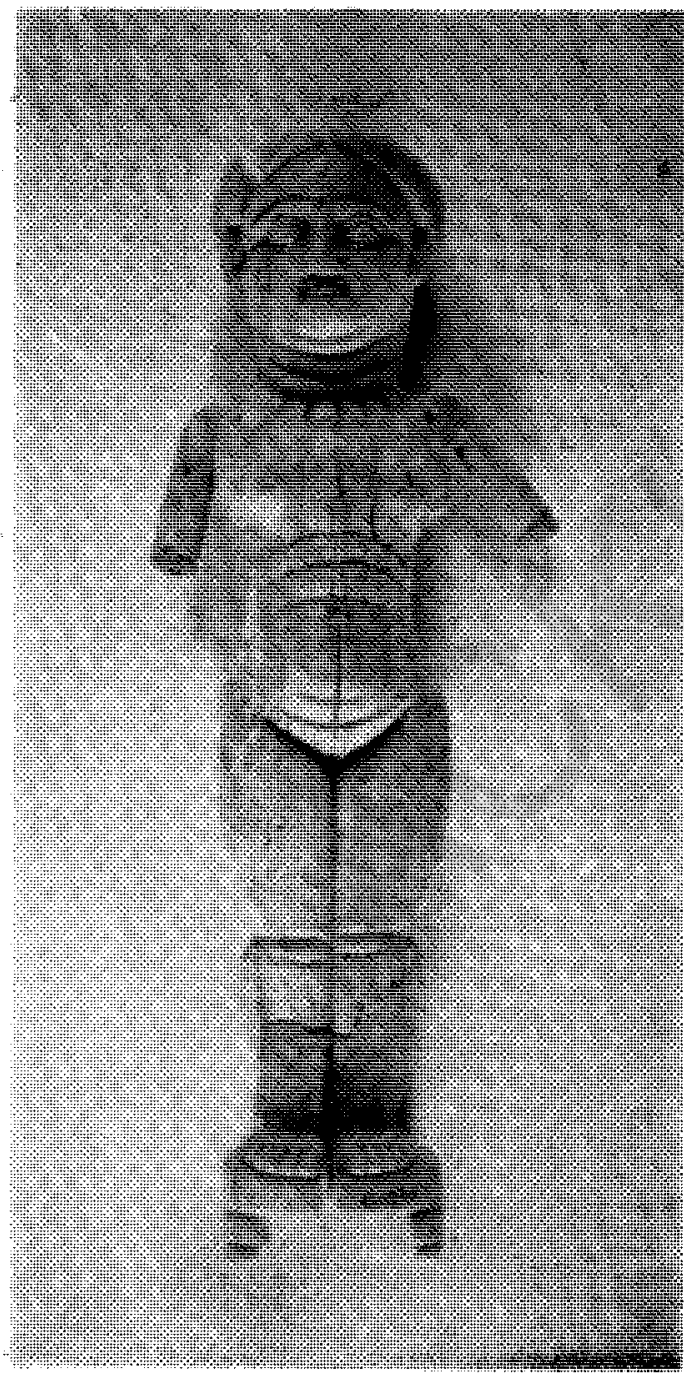

$$
\text { مجسمه ايىكه دست آن درحاكتحركت نشان داده شمه }
$$

: باد د اثشت

هديريت نشرات هر كزبينالمللى تحقيقات كو شانتِ

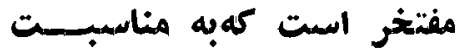

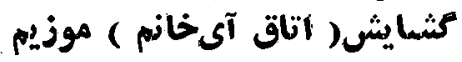

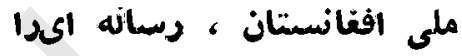
زير عنوان (آى خانم) در دو دوان

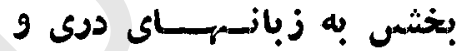

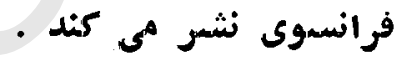

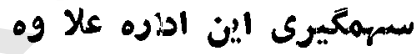

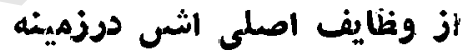

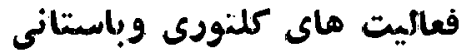

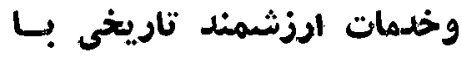
ساير ديهار تمنت ماى دياست ناريت

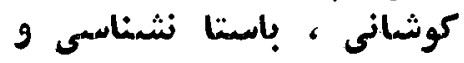

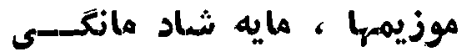
همكار ان اداره نشرات كوزيه شاد هات

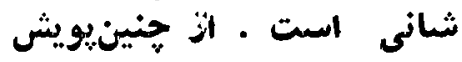

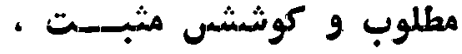
احساس با لث و ونش فرا زندكى ميكنيم كه دايم بادو يايا ـ ون وند ") 


\section{Ai Khanoum}

Gin the Occasion of the inau guration of the Ai-Khanum Hall at the National Mus eum of Afghanistan.

Kabul, May 1981

MINISTRY OF INFORMA TION AND CULTURE Yushani, Archeology and Museums Department.

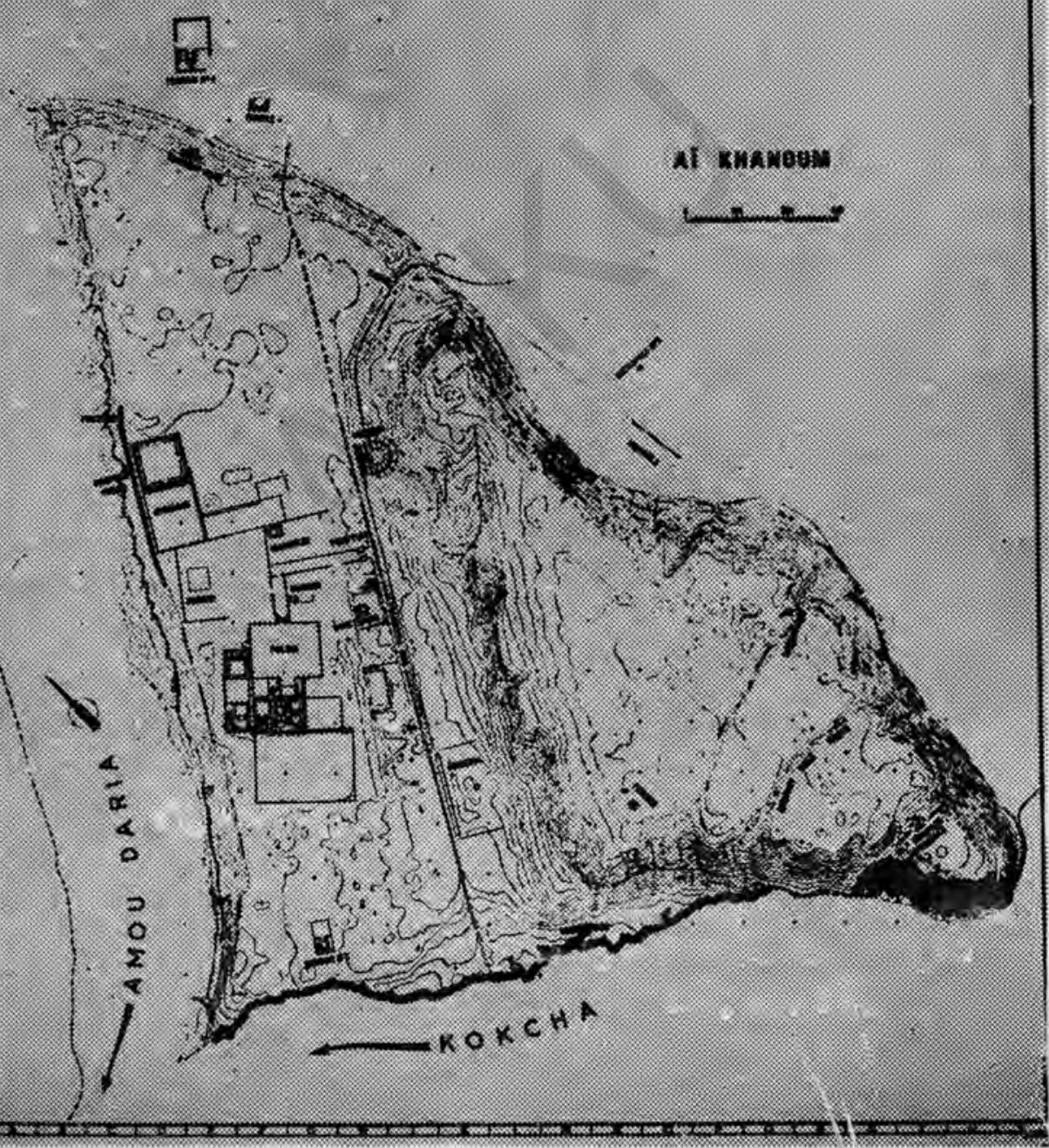

